\title{
East Ireland 1980-1994: epidemiology of neural tube defects
}

\author{
R J McDonnell, Z Johnson, V Delaney, P Dack
}

\begin{abstract}
Study objective-The objective of the study was to describe the epidemiology of neural tube defects (NTD) in the eastern region of Ireland using the EUROCAT register of congenital malformations. Design, setting and patients-EUROCAT registries monitor the prevalence of congenital anomalies in defined populations using multiple sources for case ascertainment. All cases of NTD on the Dublin EUROCAT register born between 1980 and 1994 were extracted and analysed. The crude birth prevalence rate for all NTD, spina bifida, anencephaly and encephalocoele were calculated for each year. Parameters measured were: sex ratio, stillbirth rate, proportion of low birthweight babies $(<2500 \mathrm{~g})$ and the proportion who were premature $(<37$ weeks gestation).
\end{abstract}

Main results-Of 821 NTD cases, 419 $(51.0 \%)$ had spina bifida, $322(39.2 \%)$ had anencephaly, $69(8.4 \%)$ had encephalocoele and $11(1.3 \%)$ were iniencephalic. The crude birth prevalence of NTD decreased fourfold from $46.9 / 10000$ births in 1980 to $11.6 / 10000$ in 1994. The downward trend ceased during the early 1990s. Younger mothers had significantly higher rates of NTD affected births. Twenty two per cent of NTD cases had additional non-central nervous system anomalies. In 40 cases, there was a previous family history of NTD in siblings. Seasonal effects in birth prevalence were observed. Birth notification was the most frequent mechanism of ascertainment.

Conclusion-There was a marked fall in the birth prevalence of NTD during the 15 year period. This change was real and not accounted for by pre-natal screening and diagnostic practises with termination of pregnancy, which is not legally permissible in Ireland. Dietary factors may have had an influence. Rates of NTD in this region are still higher than many other parts of Europe. Primary prevention strategies through increased folic acid intake are necessary to further reduce NTD affected births.

Health Information Unit, Eastern Health Board, Dr Steeven's Hospital, Dublin 8

Correspondence: Dr Z Johnson.

Accepted for publication 25 April 1999
Celtic countries of the British Isles are known to have high prevalence rates of NTD compared with other parts of Europe. ${ }^{1}$ Since 1980, surveillance of NTD in various parts of Europe has been carried out through EUROCAT, which is a concerted action of the European Union for the surveillance of congenital anomalies. ${ }^{2-5}$ The Dublin EUROCAT Registry has monitored NTD in counties Dublin, Kildare and Wicklow in the eastern region of Ireland from 1980 onwards. Health care services in these counties are provided by the Eastern Health Board, whose total catchment population of 1.3 million is covered by the registry. This paper describes the epidemiology of NTD in the region during the 15 year period 1980-1994.

\section{Method}

EUROCAT registries use as many data sources as possible so as to achieve a high level of case ascertainment. The Dublin registry uses birth notification forms, death certificates for children under two years, the Hospital Inpatient Enquiry Scheme (HIPE; a computerised system containing diagnostic and other details for cases discharged from paediatric and acute hospitals), karyotyping records, neonatal paediatric listings and maternity hospital necropsy. The latter source is used to ascertain stillbirths with NTD, in addition to birth notification forms. Screening with termination of pregnancy is not undertaken in Ireland for legal reasons and therefore this study is based on live and stillbirths only.

All cases of NTD on the register with birth dates between 1 January 1980 and 31 December 1994 were extracted and analysed. The following items are routinely collected for each EUROCAT case: birth date, sex, single or multiple birth, birth weight, gestation, presence of additional congenital malformations, mother's county of residence, birth date and reproductive history. The proportion of all congenital anomalies on the register accounted for by NTD was calculated. Analysis was carried out by time, place (county of residence of mother) and person. Prevalence (birth) rates per 10000 births were examined each year for the 15 year study period and by five year periods. The following factors were compared by type of NTD: prevalence, sex ratio, the proportion of cases with a birth weight less than $2500 \mathrm{~g}$, the proportion of cases born before 37 weeks gestation, the proportion of mothers under the age of 35 years and the proportion of stillbirths. Comparisons involving marital status are based on five categories as legally defined in Ireland (married, single, 


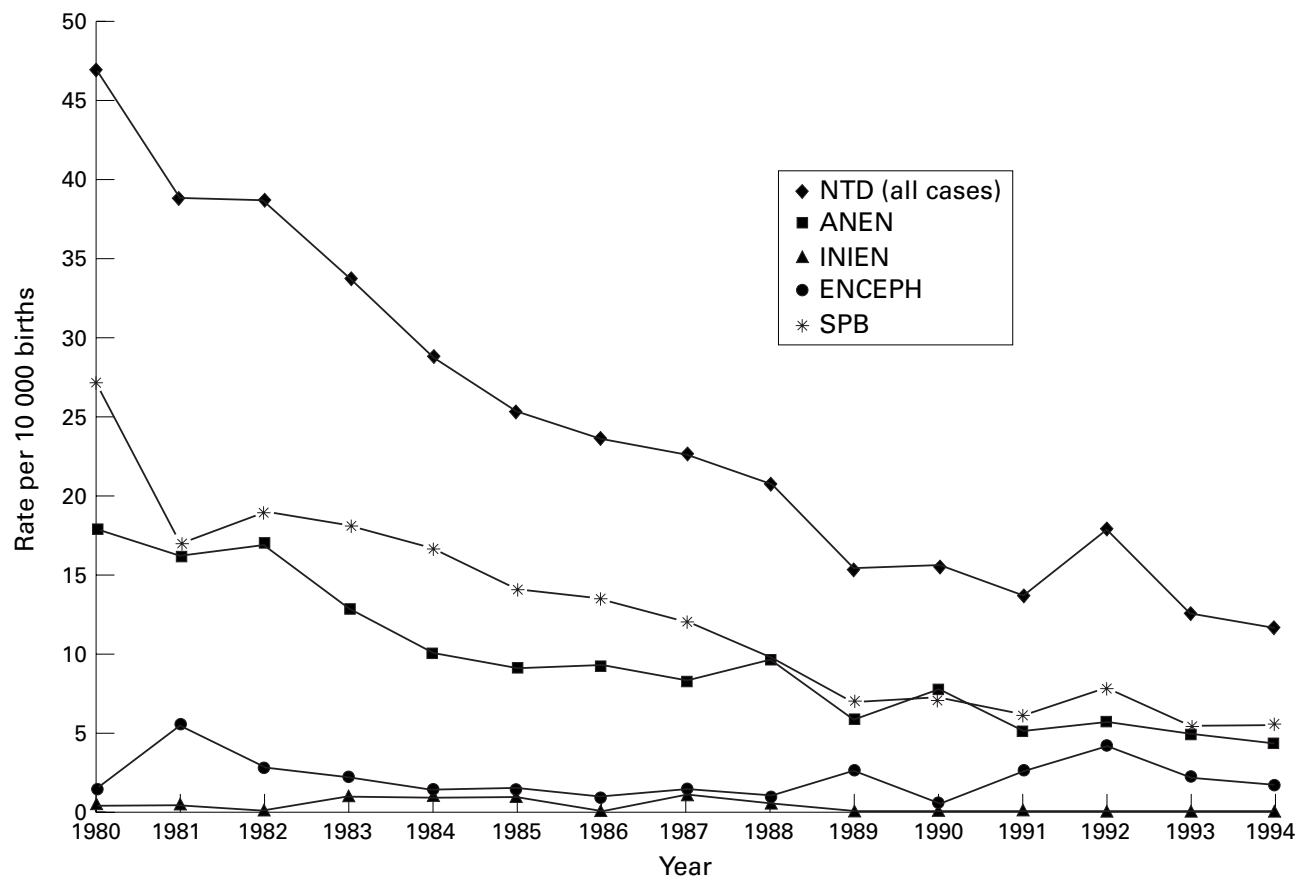

Figure 1 Trends by type of NTD 1980-1994.

widowed, separated, divorced). Information on cohabiting couples who are single according to this categorisation is not available. The effect of season of birth on prevalence and the prevalence of each type of NTD by the source of ascertainment were examined. The socioeconomic group (SEG) of NTD cases was examined; SEG is an 11 point non-ordinal scale ${ }^{6}$ and has been used by the Central Statistics Office (CSO) since 1951. The SEG of each NTD case was based on the occupation of the father of the affected child, using the coding classification of the CSO and we categorised cases as manual and non-manual based on SEG. Denominator birth data for the years 1980-

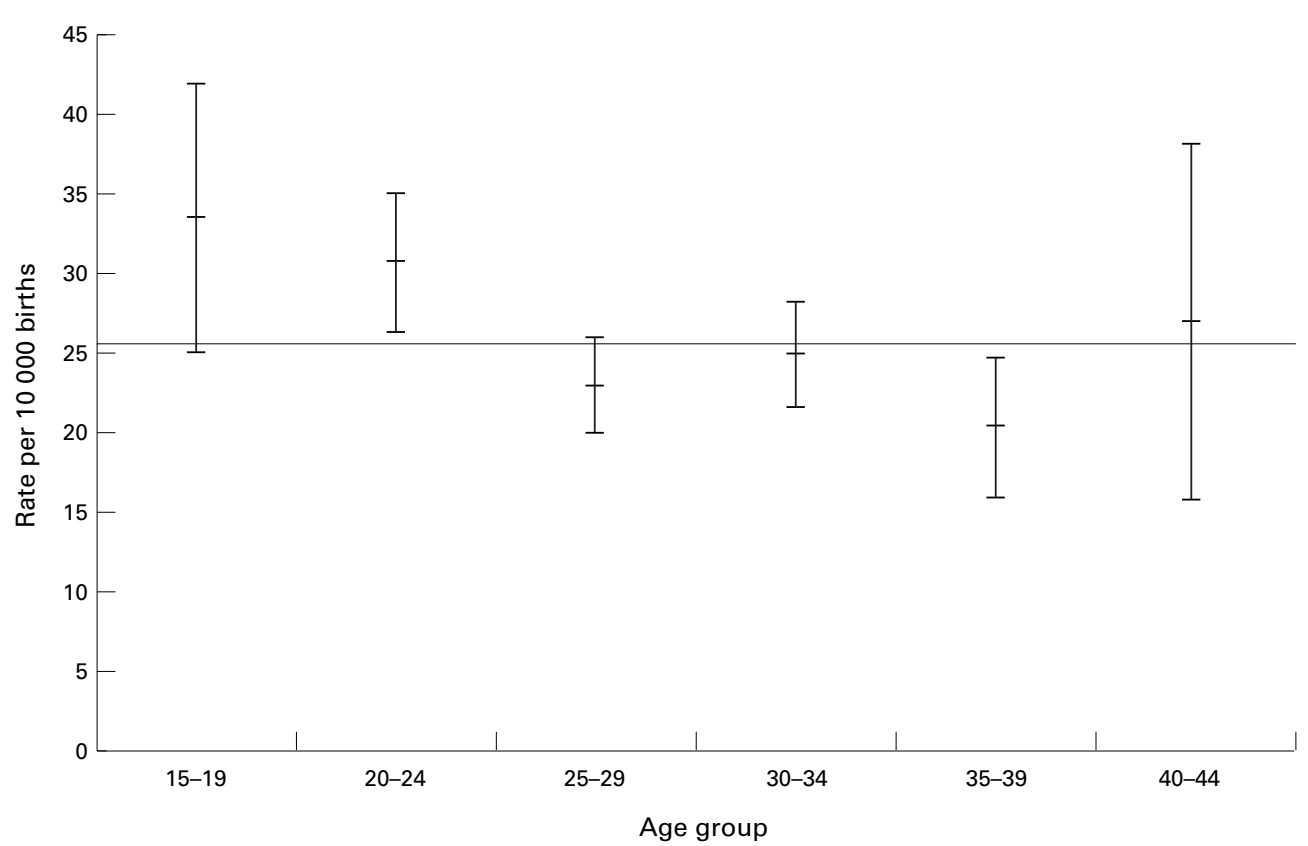

Figure 2 Age of mother at delivery and NTD rate per 10000 births (95\% CI). The reference line (25.6/10 000) refers to the overall rate of NTD for the period 1980-1994.
1994 were supplied by the CSO. The latter also provided denominator data on the occupations of fathers of children born in the Republic of Ireland from 1980-1994. Where the occupation was not stated (this frequently occurred when the mother was unmarried), the SEG was categorised as "unknown". Precurrence was defined as birth of siblings with NTD before the index case. Information on affected siblings born before the introduction of the EUROCAT register was historical and had been recorded on the data collection form of index cases born in the early 1980s. Data on NTD affected siblings of index cases born more recently were available from the register also. 


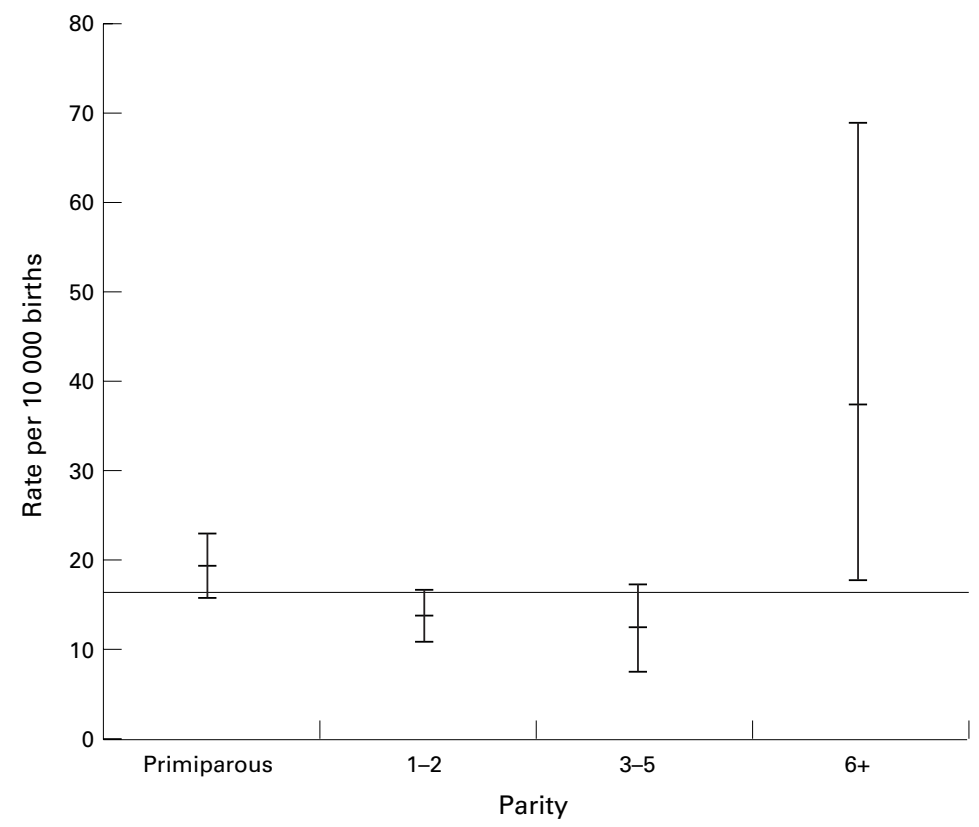

Figure 3 Rate of NTD per 10000 births and parity 1987-1994 (95\% CI). The reference line (16.3/10 000) refers to the overall rate of NTD for the period 1987-1994.

The data were analysed using SAS Version 6.07 (SAS is a registered trademark of SAS Institute Inc, Cary, NC, USA). The $\chi^{2}$ test was used for comparison of proportions and as an approximation of the Poisson heterogeneity test for comparing rates using vital statistics denominators. The software package Confidence Interval Analysis program (CIA) ${ }^{7}$ was used in calculating 95\% confidence intervals (CI) and $\chi^{2}$ for trend using Epi Info $6.04 \mathrm{a}^{8}$ for mothers' age at delivery and SEG. Seasonality tests carried out were: Edwards' test ${ }^{9}$ for a simple harmonic curve, Freedman's test ${ }^{10}$ for deviation from uniform incidence and the Ratchet circular scan test. ${ }^{11}$

\section{Results}

Between 1980-1994, there were 320750 births in the Eastern Health Board region of Ireland; 9161 children were registered with major or minor congenital anomalies on the Dublin register. Of these, $821(9.0 \%)$ had an NTD. The birth prevalence for NTD during the 15 year period was 25.6 per 10000 births in the region overall.

Of the 821 NTD cases, 419 (51.0\%) had spina bifida, $322(39.2 \%)$ were anencephalic, $69(8.4 \%)$ had encephalocoele and $11(1.3 \%)$ were iniencephalic; the corresponding birth prevalence per 10000 births was 13.1 for spina bifida, 10.0 for anencephaly, 2.2 for encephalocoele and 0.3 for iniencephaly. There were 330 $(40.2 \%)$ males, $487(59.3 \%)$ females and the sex of four cases was either unknown or

Table 1 Characterisitics of cohorts of the different types of NTD registered 1980-1994

\begin{tabular}{llllll}
\hline & $\begin{array}{l}\text { Spina bifida } \\
(n=419)\end{array}$ & $\begin{array}{l}\text { Anencephaly } \\
(n=322)\end{array}$ & $\begin{array}{l}\text { Encephalocoele } \\
(n=69)\end{array}$ & $\begin{array}{l}\text { Iniencephaly } \\
(n=11)\end{array}$ & p value \\
\hline Sex ratio (female/male) & 1.1 & 2.1 & 1.2 & 11 & $<0.001$ \\
\% Birth weight <2500 g & 14.7 & 81.5 & 29.3 & 93.8 & $<0.001$ \\
\% <37 weeks gestation & 14.0 & 55.0 & 36.0 & 71.0 & $<0.01$ \\
$\begin{array}{l}\text { Maternal age: 35+ years } \\
\text { \% Stillbirths }\end{array}$ & 9.0 & 9.0 & 12.0 & 19.0 & $\mathrm{NS}$ \\
& 10.0 & 58.0 & 22.0 & 87.0 & $<0.001$ \\
\hline
\end{tabular}

indeterminate. Figure 1 shows the trend in birth prevalence over the 15 years for all types of NTD. There were 124 NTD affected births in 1980, representing the largest number in the period and this had fallen to 21 NTD affected births in 1994. The birth prevalence rate for NTD fell from 46.9 to 11.6 per 10000 births from 1980-1994 ( $\chi^{2}$ for linear trend $=119.3$, $\mathrm{df}=1, \mathrm{p}<0.001)$ with a sharp fall during $1980 /$ 81 , followed by a more gradual decline after this, and almost levelling off from 1989 although rising again in 1992 . When the data were divided into five year periods the trend was significant for the periods $1980-1984\left(\chi^{2}\right.$ for linear trend $=11.1, \mathrm{df}=1, \mathrm{p}<0.001)$ and 1985-1989 $\left(\chi^{2}\right.$ for linear trend $=4.8, \mathrm{df}=1$, $\mathrm{p}<0.05)$ but not significant for the period 1990-1994.

The rates for spina bifida and anencephaly followed a similar pattern during the period. The birth prevalence of spina bifida declined from 27.2 per 10000 births in 1980 to 5.5 in $1994\left(\chi^{2}\right.$ for linear trend $=86.4, \mathrm{df}=1$, $\mathrm{p}<0.0001)$. Likewise, the birth prevalence of anencephaly fell from 17.8 per 10000 births in 1980 to 4.4 in 1994 ( $\chi^{2}$ for linear trend $=55.1$, $\mathrm{df}=1, \mathrm{p}<0.0001)$. In contrast, the trend had not significantly changed for encephalocoele during the 15 year period, at $1.5 / 10000$ births in 1980 and 1.65/10 000 births in 1994. The spina bifida/anencephaly ratio for the 15 year period was $1.3(419 / 322)$, the ratio of encephalocoele to other NTDs was 0.09 (69/752).

Figure 2 shows the rate of NTD with $95 \%$ confidence intervals for mothers in a range of age groups. The risk of having an NTD affected child decreased with age $\left(\chi^{2}\right.$ for linear trend $=9.6, \mathrm{df}=1, \mathrm{p}<0.01)$. The trends among the different types of NTD were similar; there was a decreasing prevalence of spina bifida as the mothers age at delivery increased $\left(\chi^{2}\right.$ for linear trend $=7.9, \mathrm{df}=1, \mathrm{p}<0.01)$; the same trend was also evident for anencephaly, although it was not statistically significant. There was no association between the rate of NTD and marital status.

We examined the relation between the rate of NTD and parity of the mother for the eight year period 1987-1994 (data on parity before 1987 were incomplete). There was no significant trend for NTD and increasing parity. The birth prevalence rate of NTD during the period was 16.3/10 000. Figure 3 shows the rate for different categories of mother's parity.

Sixteen NTD cases were births from twin pregnancies. Using national data on twinning, the risk of a child of a twin birth having NTD was estimated at $1: 441(22.7 / 10000)$ compared with 1:389 (25.6/10 000) for singleton births (NS). Of the NTD affected twins, 10 had spina bifida, four were anencephalic and two had encephalocoele. The sex of the non-NTD affected twin was available for 12 of the twin sets; all except one child was of the same sex as its sibling. One pair of twins (both female) was concordant for spina bifida. All twins except one (anencephalic) were live births.

Table 1 shows the characteristics of cohorts of the different types of NTD. The female to 


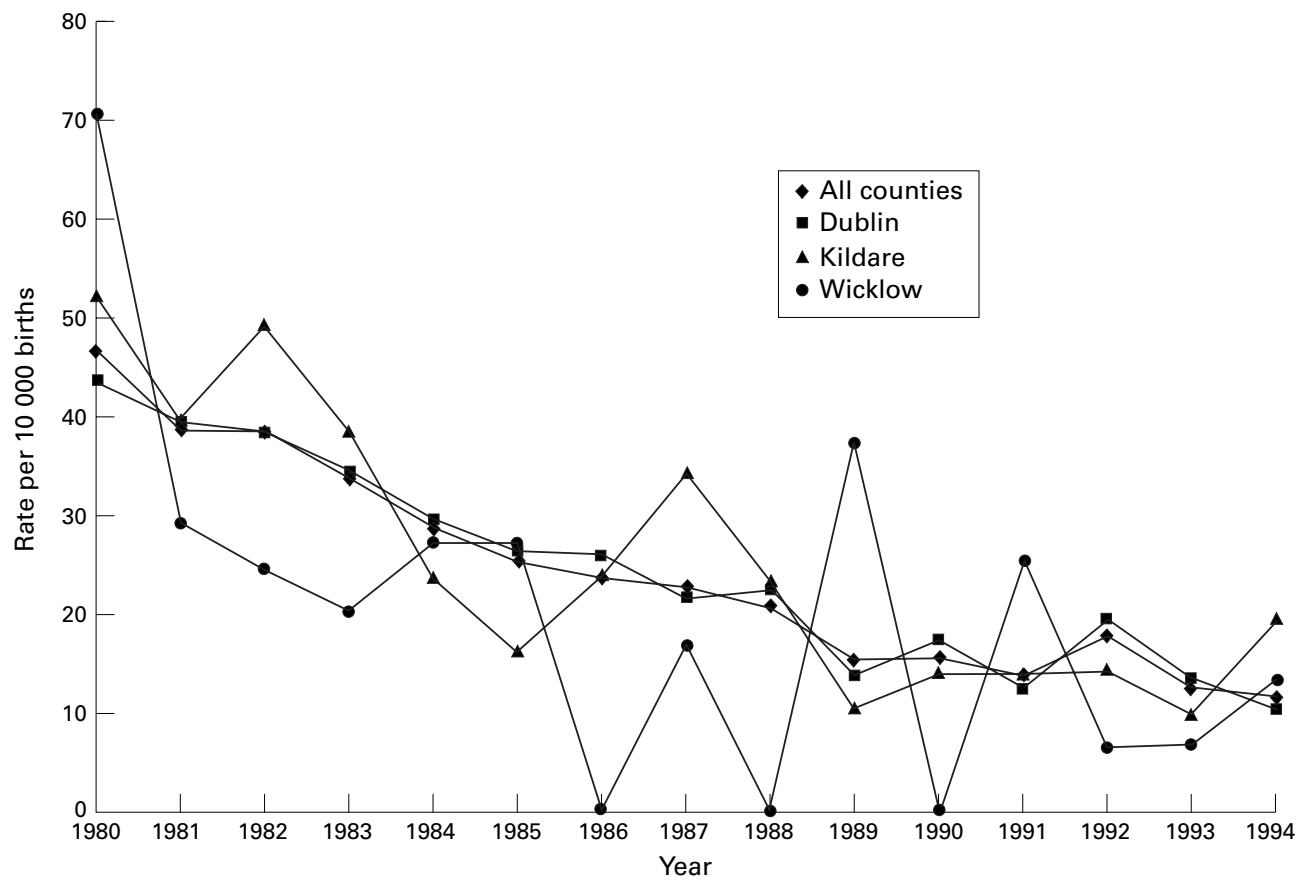

Figure 4 NTD in counties Dublin, Kildare and Wicklow 1980-1994.

male sex ratio was significantly higher for anencephalics and iniencephalics compared with spina bifida and encephalocoele. There were also significant differences between the type of NTD with regard to the proportions who were stillborn, born before 37 weeks gestation and who had a birth weight less than $2500 \mathrm{~g}$. There was little difference between the proportion of mothers aged over 35 years at delivery and the different types of NTD.

The NTD rate among mothers in manual SEGs $(26.3 / 10000,95 \%$ CI 23.3, 29.3) did not differ significantly from that of the non-manual group $(22.4 / 10000,95 \%$ CI $20.2,24.8)$. Seasonal variation in the birth prevalence of NTD during the 15 year period was observed. Birth prevalence of NTD was higher in the January-June period at 28.0/ 10000 compared with a rate of 23.2/10 000 during July-December. Although Freedman's test for any deviation from a uniform incidence was significant $(p<0.05)$, the Ratchet circular scan test and Edwards' test did not reach significance. The peak prevalence occurred in April. When the data were examined by five year periods, a seasonal effect was only observed during the period 1985-89; the Ratchet circular scan test and Edwards' test were significant $(p<0.05)$ with the peak prevalence in May, and Freedman's test was also significant $(\mathrm{p}<0.05)$.

In 40 of the NTD cases, there was a previous family history of NTD in siblings. The total number of siblings of these cases was 1865 giving a precurrence rate for NTD of $2.1 \%$ (40/1865), corresponding to a rate of $214 /$ 10000 siblings. In 57 of the NTD cases there were other siblings previously affected with a congenital anomaly (including NTD) giving a precurrence rate for all congenital anomaly of $3.1 \%(57 / 1865)$.
The number of NTD affected births in counties Dublin, Kildare and Wicklow during the period 1980-1994 were 668, 96 and 57 respectively with corresponding prevalences per 10000 births of 25.8 (95\% CI 23.9, 27.8) for Dublin, 27.0 (95\% CI 21.6, 32.5) for Kildare, and 21.5 (95\% CI 15.9, 27.1) for Wicklow. Figure 4 shows the trend in NTD birth prevalence in each county. The Wicklow rate showed considerable year to year variation, particularly from 1986-1991 but the overall rate did not differ significantly from counties Dublin and Kildare combined. There was a significant downward trend from 1980-1994 for Dublin $\left(\chi^{2}\right.$ for linear trend $=104, \mathrm{df}=1$, $\mathrm{p}<0.001)$ and Kildare $\left(\chi^{2}\right.$ for linear trend=17.8, $\mathrm{df}=1, \mathrm{p}<0.001$ ) but not for Wicklow.

Of the 821 NTD cases in the study, there were $184(22.4 \%)$ cases with additional non-central nervous system (non-CNS) anomalies recorded; 113 had one additional anomaly, 29 had two and 42 had three or more. The total number of anomalies for all cases was 326 , table 2 shows the main categories of additional anomaly. Cystic anomalies (16/48) and renal agenesis/dysgenisis (14/48) were the most frequent kidney anomalies recorded and the most frequent cardiovascular anomaly was ventricular septal defect (9/35). Nineteen cases

Table 2 Most frequent non-CNS additional anomalies

\begin{tabular}{lll}
\hline Additional anomaly & Number & $\begin{array}{c}\text { \% Of total } \\
\text { anomalies }\end{array}$ \\
\hline Anomalies of the kidneys/urinary tract & 48 & 14.7 \\
Anomalies of cardiovascular system & 35 & 10.7 \\
Abdominal wall anomalies & 19 & 5.8 \\
Lung anomalies & 18 & 5.5 \\
Anomalies of the diaphragm & 16 & 4.9 \\
Intestinal anomalies & 15 & 4.6 \\
Congenital dislocation of hip (unilateral) & 12 & 3.7 \\
\hline
\end{tabular}


Table 3 Most frequent sole source of ascertainment for NTD types

\begin{tabular}{|c|c|c|c|c|c|c|c|c|}
\hline \multirow[b]{2}{*}{ Ascertainment source } & \multicolumn{2}{|c|}{ Spina bifida $(n=73)$} & \multicolumn{2}{|c|}{ Anencephaly $(n=64)$} & \multicolumn{2}{|c|}{ Encephalocoele $(n=27)$} & \multicolumn{2}{|c|}{ All NTD $(n=164)$} \\
\hline & $\begin{array}{l}\% \text { Ascertained } \\
\text { if source } \\
\text { omitted }\end{array}$ & $\begin{array}{l}\% \text { Ascertained } \\
\text { if only source }\end{array}$ & $\begin{array}{l}\% \text { Ascertained } \\
\text { if source } \\
\text { omitted }\end{array}$ & $\begin{array}{l}\% \text { Ascertained } \\
\text { if only source }\end{array}$ & $\begin{array}{l}\% \text { Ascertained } \\
\text { if source } \\
\text { omitted }\end{array}$ & $\begin{array}{l}\% \text { Ascertained } \\
\text { if only source }\end{array}$ & $\begin{array}{l}\% \text { Ascertained } \\
\text { if source } \\
\text { omitted }\end{array}$ & $\begin{array}{l}\% \text { Ascertained } \\
\text { if only source }\end{array}$ \\
\hline Birth notification & 94.5 & 68.5 & 78.1 & 79.7 & 92.6 & 74.1 & 87.8 & 73.8 \\
\hline Acute hospitals & 95.9 & 60.3 & 100 & 0 & 81.5 & 48.2 & 95.1 & 34.8 \\
\hline Pathology/laboratory & 94.5 & 37.0 & 90.6 & 56.3 & 100 & 29.6 & 93.9 & 43.3 \\
\hline Neonatal units & 97.3 & 28.8 & 95.3 & 20.3 & 96.3 & 14.8 & 96.3 & 23.2 \\
\hline
\end{tabular}

of NTD had abdominal wall anomalies, for example, omphalocoele or gastroschisis. There was no significant difference between children born with NTD alone and those with additional anomalies with regard to sex, the proportion weighing under $2500 \mathrm{~g}$, the proportion born before 37 weeks gestation or the proportion who were stillborn.

Information on source of ascertainment for each NTD case was available for the period 1989-1994 only. There were 164 cases of NTD during this six year period. In $26.8 \%$ $(44 / 164)$ there was one sole source of ascertainment. Table 3 shows the percentage ascertainment from different sources. As a sole source of ascertainment, birth notification provided a higher percentage of cases than any of the other sources. No cases of anencephaly were ascertained through acute hospitals whereas $60.3 \%$ of spina bifida cases were ascertained through this source.

\section{Discussion}

Our study is population based and covers a 15 year period of NTD affected births in a defined geographical region in the east of Ireland with a combined population of 1.3 million (one third of the population of the state). Previous studies of the epidemiology of NTD in Ireland have primarily been hospital based on births in Dublin maternity hospitals using the total number of births in the hospitals as the denominator. A retrospective study of anencephaly and spina bifida ${ }^{12}$ during the years 1953-54 and 1961-82 showed a decreasing trend in NTD from 85.4/10 000 in 1954 to 38.0 in 1982. Another study ${ }^{13}$ found an incidence of 65/10 000 in the period 1970-75. Although hospital based, these studies use similar definitions of NTD, and their findings generally concur with our study, reflecting a fall in the rate of NTD from the very high levels seen before 1980 to the lower rates of the early 1990s. Another Dublin hospital based study of spina bifida alone ${ }^{14}$ for the period 1966-77 showed an incidence of 39/10 000 for spina bifida, but included spina bifida occulta and isolated hydrocephalus in their definition of NTD. There is little information on rates of NTD in other parts of the country, apart from that available from the Galway EUROCAT register, ${ }^{2}$ with an NTD rate of 19.3/10 000 births during the same study period as ours. A previous hospital based study ${ }^{15}$ in the same region showed an incidence of 29.6/10 000 births for the period 1974-85. A population based study ${ }^{16}$ of NTD covering the five year period 1979-84 using early EUROCAT data showed an NTD birth prevalence of 39/10 000 births; the data used are included in the 15 year period covered by our study.

The "Celtic" countries of the British Isles have had a much higher prevalence of NTD during the past 16 years compared with other European countries. ${ }^{2}$ Although the birth prevalence of NTD has been falling in European and other developed countries ${ }^{217} 18$ since the early 1980 s, partly attributable to prenatal diagnosis of NTD and selective termination, the total prevalence of NTD (including live births, stillbirths and terminations) has remained relatively stable. This has not been the case in the British Isles. ${ }^{2}$ The dramatic fall in the birth prevalence of NTD shown in our study is likely to be real and not influenced by pre-natal diagnostic practises as termination of pregnancy in Ireland is not legally permissible. Residents may travel outside the state to obtain a termination, however, the numbers taking this route are very small (personal communication, National Statistics Office, London) and unlikely to have influenced the overall prevalence during the study period. The absence of pre-natal screening/termination of pregnancy in Ireland allows description of the epidemiology of NTD under "natural" conditions. Such a study would not be possible in other European countries where termination of pregnancy is legal. The decreasing trend in NTD prevalence observed was most dramatic before the introduction of campaigns in the early 1990 s aimed at increasing folic acid intake among women of childbearing age. A similar fall in total prevalence of NTD has also been reported in other Celtic areas of the British Isles. It is unclear why there has been such a marked decline in NTD rates in Ireland since the early 1980s and what environmental factors, if any, may have been responsible or contributed to it. There are no reliable data available on the use of vitamin supplements by women in Ireland before 1995. Changes in patterns of dietary intake over the past 30 years associated with economic prosperity and all year round availability of foods such as vegetables (particularly those containing folic acid) may have had some influence. Overall vegetable consumption increased rapidly in the late 1970s and fell off in the early 1980s before rising again; however, Ireland is still one of the lowest vegetable and fruit consumers in the European Union. ${ }^{19}$ The major producer of breakfast cereals in Ireland began fortifying all their cereals with folic acid since 1987 (personal communication, Kellogg's, UK).

Our study also showed a higher risk of NTD among younger mothers as has been observed in other studies, ${ }^{20}{ }^{21}$ this may in part be 
attributable to a lower folic acid content in diets of younger women; a national nutrition survey $^{22}$ in Ireland in 1990 showed a lower daily folate intake among women aged less than 25 years than those aged 25 to 40 years (the daily folate intake of women over 40 years of age was also lower).

The spina bifida to anencephalic ratio and the encephalocoele to all NTD ratio are similar to those reported previously for the British Isles as a whole. $^{23}$ The predominance of female anencephalic births over males in our study is similar to that seen in other countries and likewise the slight female predominance in spina bifida births. Not surprisingly, anencephalic and iniencephalic affected births had the worst outcome in terms of the proportions who were stillborn and low birthweight, consequent on the severe and lethal nature of the abnormality. Although the non-manual SEGs had a lower rate of NTD in our study, this was not significant. Studies elsewhere have shown lower rates among those where the father's work was non-manual. ${ }^{20} 2124$

We defined the index case as that which was ascertained and registered in the Dublin EUROCAT registry, although some of these had siblings born with NTD before the establishment of the registry. We therefore calculated precurrence rates rather than recurrence rates for NTD cases. The precurrence rate of NTD among family siblings at $2.1 \%$ was higher than that seen in a study of precurrence of congenital anomaly in southern Belgium ${ }^{25}$; Elwood, Little and Elwood ${ }^{24}$ cite a general precurrence rate in Europe of $4.6 \%$ and that precurrence and recurrence rates do not significantly differ.

Previous research has shown a predominance of NTD births in the winter months ${ }^{26} 27$ particularly in October to December and January to March in the British Isles. This contrasts with a peak in April/May in our study that seems to have been determined by the significant variation during the five year period 1985-89, without much seasonal variation during the other five year periods. However, these results should be interpreted with caution as there is an overall long term downward trend in the data. In a previous Irish study ${ }^{28}$ an April peak was also observed.

There was substantial fluctuation in the rate of NTD in two of the three counties - that is, Kildare and Wicklow. In some years, no NTD births were recorded in Wicklow. However, each year Dublin has approximately four times the number of births of the other two counties combined and the NTD birth prevalence in Dublin therefore was the major determinant of the overall trend for the three counties combined.

The importance of using multiple sources of ascertainment is demonstrated by the finding that more than half of spina bifida cases were ascertained through acute hospitals; in contrast, no cases of anencephaly were ascertained from this source. This is likely to be a consequence of anencephaly being easily identifiable at birth with its associated high mortality, whereas cases of spina bifida may be admitted to acute hospitals for care before ascertainment to the registry.

By the mid-1990s the birth prevalence of NTD in this region of Ireland seems to have levelled off at a rate that is still higher than that of many European regions. Our research team found in 1997 that $16 \%$ of pregnant women were taking peri-conceptional folic acid. ${ }^{29}$ The protective effect of folic acid in the prevention of recurrence ${ }^{30}$ and primary occurrence ${ }^{3132}$ of NTD has been demonstrated previously. Therefore, if peri-conceptional folic acid use increased to $100 \%$, we could expect a substantial fall in the number of NTD cases in Ireland. It is essential that all women are aware of the importance of peri-conceptional folic acid and are taking it. Fortification of staple foodstuffs in Ireland is under urgent consideration also, as an effective way of increasing folate intake.

The authors wish to acknowledge Norita Griffin of the Central Statistics Office for the provision of denominator data, Ann Clifton in the Economic and Social Research Institute for her assistance with HIPE data, and Des Duff of Our Lady's Hospital Crumlin for his help with outpatient data.

Conflicts of interest: none.

1 The EUROCAT Working group, De Wals P, Dolk H, Weatherall J, et al. Prevalence of neural tube defects in 16 regions of Europe, 1980-83. Int F Epidemiol 1987;16:24651 .

2 EUROCAT Working Group. EUROCAT Report 7. Brussels: EUROCAT, 1997

3 Lechat M, Dolk $H$. Registries of congenital anomalies: EUROCAT. Environ Health Perspect 1993;101:153-7.

EUROCAT. Environ Health Perspect 1993;101:153-7.
4 The EUROCAT Working group, De Wals P, Dolk H, Bertrand F, et al. Epidemiologic surveillance of congenital anomalies: The EUROCAT project. Acta Paediatr Lat 1988;41:641-58.

5 Wals de P, Dolk H, Bertrand F, et al. Epidemiologic surveilance of congenital anomalies by the EUROCAT registry. Rev Epidemiol Sante Publique 1988;36:273-82.

6 O'Hare A, Whelan C, Commins P. The development of an Irish census based social class scale. The Economic and Social Review 1991;22:135-56.

7 Gardner M, Gardner S, Winter P. Confidence intervals analysis (CIA) microcomputer program manual. London: BMJ Publishing Group, 1992.

8 Dean A, Dean J, Coulombier D, et al. Epi Info, Version 6. A word processing, database, and statistics program for epidemiology on microcomputer. Atlanta: Centres for Disease Control ogy on microcomputer.
and Prevention, 1994.

9 Edwards J. Seasonal incidence of congenital disease in Birmingham. Ann Hum Genet 1961;25:89-93.

10 Freedman L. The use of a Kolmogorov-Smirnov type statisic in testing hypotheses about seasonal variation. I Epidemiol Community Health 1979;33:223-8.

11 Wallenstein S, Weinberg C, Gould M. Testing for a pulse in seasonal event data. Biometrics 1989;45:817-30.

12 Coffey V. Neural tube defects in Dublin 1953-1954 and 1961-1982. Ir Med F 1983;76:411-13.

13 Mc Carthy P, Dalrymple I, Duignan N, et al. Recurrence rates of neural tube defects in Dublin maternity hospitals. Ir Med F 1983;76:78-9.

14 Sheridan-Pereira M, Hensey O, O'Brien N. Spina bifida and neural tube defects. Ir Med F 1982;75:163-4.

15 O'Dowd M, Connolly K, Ryan A. Neural ube defects in rural Ireland. Arch Dis Child 1987;62:297-8.

16 Radic A, Dolk H, De Wals P. Declining rate of neural tube Radic A, Dolk H, De Wals P. Declining rate of neural tube
defects in three eastern counties of Ireland: 1979-1984. Ir Med $\mathcal{F}$ 1987;80:226-8.

17 Chan A, Robertson E, Haan E, et al. Prevalence of neural tube defects in South Australia, 1966-91: effectiveness and impact of prenatal diagnosis. BMF 1993;307:703-6.

18 Lary J, Edmonds L. Prevalence of spina bifida at birth United States, 1983-1990: a comparison of two surveilance systems. MMWR CDC Surveill Summ 1996;45:1526.

19 National Nutrition Surveillance Centre. Changes in the food chain since the time of the great Irish famine. Galway: University College Galway, 1995.

20 Friel J, Frecker M, Fraser F. Nutritional patterns of mothers of children with neural tube defects in Newfoundland. Am 7 Med Genet 1995;55:195-9.

21 Buccimazza S, Molteno C, Dunne T, et al. Prevalence of neural tube defects in Cape Town, South Africa. Teratology 1994;50:194-9.

22 Irish Nutrition and Dietetic Institute. Irish National Nutrition Survey 1990. Dublin: Irish Nutrition and Dietetic Institute, 1990. 
23 Dolk H, De Wals P, Gillerot Y, et al. Heterogeneity of Neural Tube Defects in Europe: the significance of site of defect and presence geographic differences in prevalence. Teratology 1991;44 $547-9$

24 Elwood JM, Little J, Elwood JH. Epidemiology and control of neural tube defects. Oxford: Oxford University Press, 1992. 25 Lys F, Bertrand F, Gelin C, et al. Precurrence rates of malformation in families, based on registries of congenital malformations (EUROCAT). Proceedings of the first international meeting of the Genetic and Reproductive Epidemiology Research Society(GRERS). Milan: Ghedini Editore, 1992

26 Office for Population Censuses and Surveys. Congenital malformation statistics: notifications 1981-85. London: HMSO, 1988.

27 Rogers S, Weatherall J. Anencephalus. London: HMSO, 1976.
28 Elwood JH. Anencephalus in Belfast, incidence and secular and seasonal variations 1950-66. Br F Prev Soc Med 1970; 24:78-88

29 McDonnell R, Johnson Z, Doyle A, et al. Determinants of folic acid knowledge and use among antenatal women. $f$ Public Health Med 1999;21:145-9

30 MRC Vitamin Study Group. Prevention of neural tube defects: results of the Medical Research Council vitamin defects: results of the Medical
study. Lancet 1991;338:131-7.

31 Czeizel A, Dundus I, Prevention of the first occurrence of neural tube defects by peri-conceptional vitamin supplementation. N Engl f Med 1992;327:1832-5.

32 Kirke P, Daly L, Elwood J. A randomised trial of low dose olic acid to prevent neural tube defects. Arch Dis Child 1992;67:1442-6. 